\title{
Avaliação do controle radioquímico do Ricinus communis L. e Tc-99m na marcação de hemácias
}

\author{
Kristiana C. Mousinho, ${ }^{*}, 1$ Marília B. L. Correia, ${ }^{2}$ André Luiz S. Barros, ${ }^{2}$ Simey de Souza L. P. \\ Magnata, ${ }^{2}$ Ivone A. de Souza, ${ }^{1}$ Maria Teresa J. A. Catanho ${ }^{2}$ \\ ${ }^{1}$ Departamento de Farmácia, Universidade Federal de Pernambuco, Av. Prof. Morais Rego, 1236, Cidade \\ Universitária, 50670-901 Recife-PE, Brasil, \\ ${ }^{2}$ Departamento de Biofisica, Universidade Federal de Pernambuco, Av. Prof. Morais Rego, 1236, Cidade \\ Universitária, 50670-901 Recife-PE, Brasil
}

\begin{abstract}
RESUMO: O Ricinus communis L. pertence à família das Euforbiáceas, possui frutos típicos de onde é extraído o óleo de rícino, altamente tóxico. Neste estudo foi analisado o efeito do extrato de Ricinus communis L na marcação de hemácias com Tc-99m através do controle radioquímico. Os resultados mostraram que no controle radioquímico por meio da cromatografia, foi observado que o extrato marcado com Tc-99m mostrou duas frações com 130.007 e 494.592 cpm, e na marcação de hemácias, com \%ATI de 61.88 e $41.32 \%$ nas frações 1 e 2 . Foi concluído que o extrato de $R$. communis L. altera a captação do Tc-99m in vitro, competindo com o material radioativo em possíveis sítios de ligação nas células vermelhas do sangue, como a capacidade de oxidação do íon estanoso ou por competição com o íon pertecnetato.
\end{abstract}

Unitermos: Ricinus communis, Tecnécio-99m, controle radioquímico, marcação de hemácias.

\begin{abstract}
Assessment of the radiochemical control of Ricinus communis L. and Tc99m with the labeling of red blood cells". Ricinus communis L. belongs to the Euphorbiaceae family, from whose fruits the ricin oil is extracted, highly toxic. In this study it was analyzed the effect of the extract of Ricinus communis L. in the labeling of red blood cells with Tc-99m through the radiochemical control. The results showed that in the radiochemical control through chromatography, it was observed that the extract labeled with Tc-99m showed two fractions with 130.007 and $494.592 \mathrm{cpm}$, and in the labeling of red blood cells, with \%ATI of 61.88 and $41.32 \%$ in the fractions 1 and 2. It has been concluded that the extract of Ricinus communis alters the captivating of Tc-99m in vitro, competing with the radioactive material in the possible binding sites of the red blood cells, as well in the capacity of oxidation of the stannous ion or by competition with the pertechnetate ion.
\end{abstract}

Keywords: Ricinus communis, Technetium-99m, radiochemical control, labeling of red blood cells.

\section{INTRODUÇÃO}

O Tecnécio-99m ( ${ }^{99 m} \mathrm{Tc}$ ) é o radionuclídeo mais utilizado na medicina nuclear (Hwang et al., 2002), possuindo características físicas aceitáveis: meia-vida de 6 horas, emissão fóton gama de $140 \mathrm{keV}$, impacto ambiental desprezível e baixa exposição da radiação para o paciente (Oliveira et al., 2002). O uso dos produtos naturais nos estudos experimentais tem aumentado consideravelmente no mundo (BernardoFilho et al., 2005; Paoli et al., 2008).

Ricinus communis L. pertence à família das Euforbiáceas, com frutos típicos onde é extraído o óleo de rícino, que é muito utilizado como laxante, purgativo e como lubrificante na indústria (Corrêa, 1984; Olsnes, 2004; Souza et al., 1994; Agra et al., 2007; 2008).

Neste estudo foi avaliado o efeito da fração não oleosa do Ricinus communis na marcação das células sanguíneas com frações do extrato marcado com
Tecnécio-99m.

\section{MATERIAIS E MÉTODOS}

\section{Coleta da planta e extração}

Ricinus communis L. foi coletado em Pernambuco, identificado pela Dra. Marlene Barbosa e a espécie registrada no Herbário Geraldo Mariz, com número 52.116, da Universidade Federal de Pernambuco (UFPE, Brasil). O material botânico foi obtido por trituração e extraído em solução hidroetanólica 8:2 $(\mathrm{v} / \mathrm{v})$. Para a retirada do óleo de rícino foi acrescentado acetona e concentrado em seguida a vácuo, obtendo a fração não oleosa.

\section{Controle radioquímico}

Para a coluna cromatográfica de filtração foi 


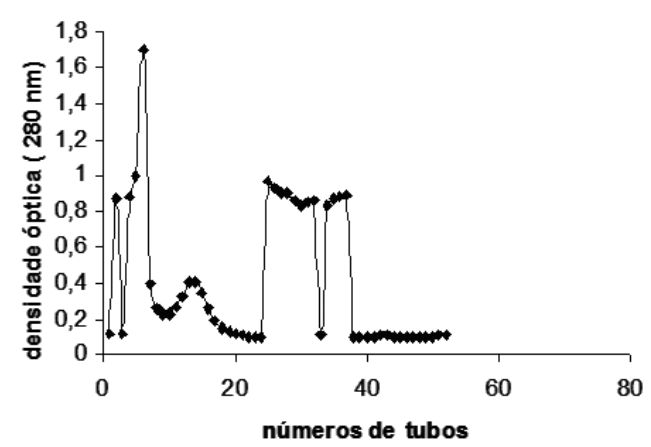

Figura 1. Frações de proteínas do extrato puro passado na coluna de cromatografia de filtração.

utilizado para a fase estacionária Sephadex $\mathrm{G} 100^{\circledR}$, sendo compactado com solução salina $0,9 \%$. O extrato de Ricinus communis foi diluído com Tween 80 à $0,2 \%$ e solução salina $0,9 \%$ na concentração de $1,0 \mathrm{mg} /$ $\mathrm{mL}$. O extrato frio não marcado foi eluído na coluna obtendo as frações de $1 \mathrm{~mL}$, coletadas e analisadas através do espectrofotômetro à $280 \mathrm{~nm}$. Em seguida foi realizada a reação de pertecnetato com cloreto estanoso por 10 minutos, cromatografado obtendo as frações e feito a contagem da radioatividade no contador gama. Posteriormente, a concentração do extrato de $1,0 \mathrm{mg} /$ $\mathrm{mL}$ foi incubada na presença do Tc- $99 \mathrm{~m}(0,1 \mathrm{~mL}$ de Tc$99 \mathrm{~m}$ e $0,9 \mathrm{~mL}$ do extrato), passando então pela coluna e coletada as frações, onde foi feita a contagem da radiação.

\section{Marcação de hemácias com extrato marcado}

A marcação das hemácias foi realizada com extrato marcado após a cromatografia, utilizando as duas frações obtidas anteriormente no controle radioquímico. O sangue foi obtido através de punção cardíaca em rato Wistar e heparinizado, colocado em contato com as duas frações coletadas do extrato marcado com Tc$99 \mathrm{~m}$. Para o controle foi utilizada solução salina $0,9 \%$,

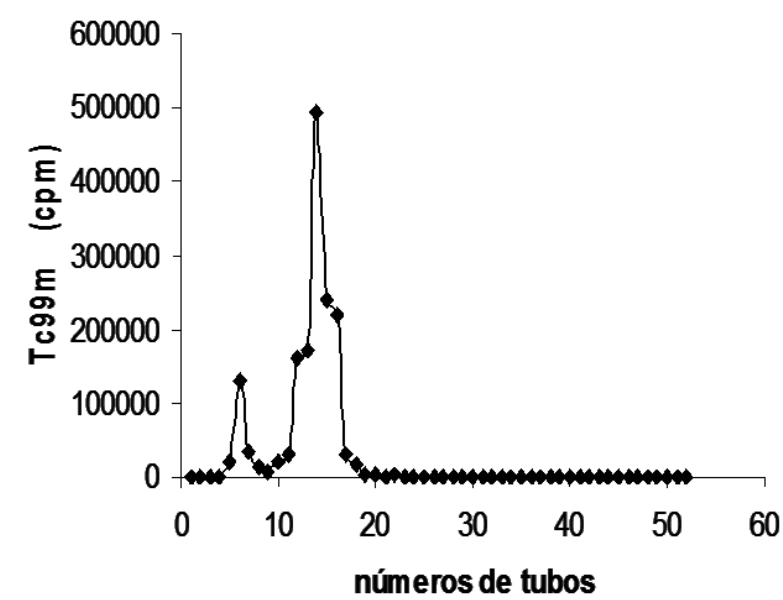

Figura 3. Frações do extrato marcado de $R$. communis com Tc$99 \mathrm{~m}$ passado na coluna de cromatografia de filtração.

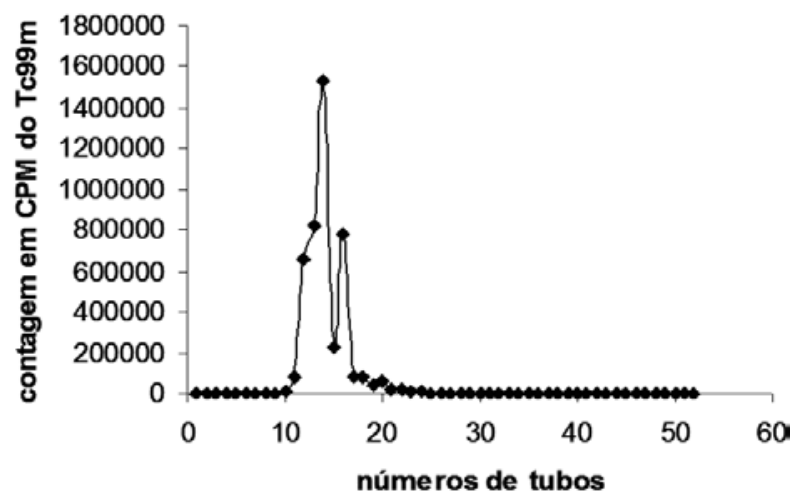

Figura 2. Frações do Tc-99m puro passado na coluna de cromatografia de filtração em gel.

incubados por 10 minutos e centrifugado os tubos para a separação do plasma e hemácias, sendo feita à contagem da radiatividade no contador gama.

O protocolo utilizado foi aprovado pelo Comitê de Ética Experimental da UFPE.

\section{Análise estatística}

A análise estatística dos dados foi feita por meio do Teste T-Student, obtendo-se significância com $\mathrm{p}<0,05$, utilizando-se Microsoft Excel Version 7.0 e Graph Pad Prism Version 3.02.

\section{RESULTADOS}

Para a análise radioquímica do extrato puro de R. communis, a Figura 1 mostra as frações obtidas pela cromatografia de filtração em gel, obtendo duas frações iniciais de 2 e 0,405 em absorbância, leitura feita no espectrofotômetro à $280 \mathrm{~nm}$, onde foi observada a expressão da proteína tóxica nestas frações. Já a análise radioquímica do Tc-99m puro, na Figura 2, mostra as frações obtidas pela cromatografia de filtração em gel, obtendo duas frações, com maior atividade de radiação em cpm de 1.527 .880 e outra 778.043 , respectivamente. A leitura foi feita no contador gama, onde se observou a expressão do Tc-99m nestas frações.

$\mathrm{Na}$ determinação da análise radioquímica do

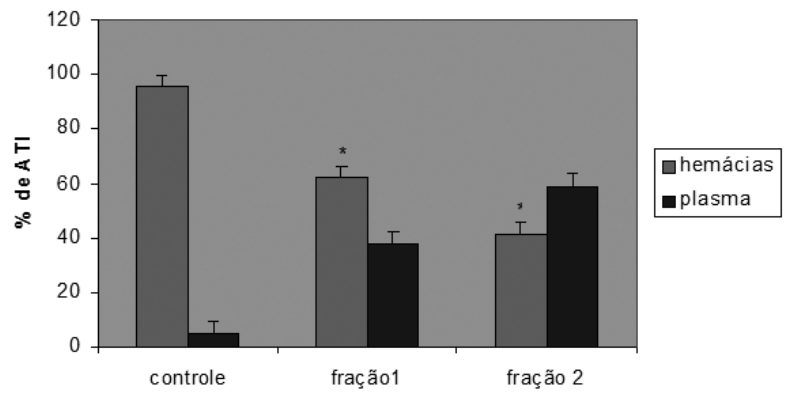

Figura 4. Frações do extrato marcado de $R$. communis com Tc$99 \mathrm{~m}$ na marcação de células sanguíneas, hemácia e plasma, com $\mathrm{p}<0,05$. 
extrato marcado de $R$. communis com Tc-99m, a Figura 3 mostra as frações obtidas pela cromatografia de filtração em gel nas duas frações, uma que corresponde a fração não oleosa do extrato e outra que corresponde a radiação do Tc-99m isolado, com contagem de 130.007 e $494.592 \mathrm{cpm}$, respectivamente. A leitura foi realizada no contador gama, onde se observa a expressão da proteína tóxica marcada com Tc-99m nestas frações. Enquanto que a figura 4 apresenta a marcação das células sangüíneas do extrato marcado com Tc-99m, após eluição, foi verificado que o extrato comparado as hemácias marcadas com Tc-99m apresenta um \%ATI de 61,88 e 41,32 nas frações 1 e 2, respectivamente.

\section{DISCUSSÃO E CONCLUSÃO}

Diante do exposto, esse trabalho mostrou o controle radioquímico através da cromatografia de filtração, onde foi observado que o extrato marcado com Tc-99m apresentou duas frações com 130.007 e $494.592 \mathrm{cpm}$, e que estas frações foram analisadas pela marcação das células sanguíneas, com \% de ATI de 61,88 e $41,32 \%$ nas frações 1 e 2 , respectivamente, sendo estes resultados estatísticamente significativos, mostrando que o extrato de $R$. communis compete com o Tc-99m na ligação com as hemácias ficando mais livre no plasma.

Segundo Lugnier et al. (1980) as propriedades físicas e químicas da ricina foram estudadas em coluna cromatográfica com Sephadex G100 ${ }^{\circledR}$ para obtenção da massa molecular de 51.000 à 58.000. No mesmo estudo foi feita a cromatografia de DEAE - celulose, onde a ricina foi encontrada em duas frações. Esse resultado comprova o nosso trabalho, onde também obtivemos duas frações e que provavelmente a proteína encontrada é a ricina, que é descrita em vários trabalhos como antitumoral. Alguns trabalhos também mostram a interferência dos produtos naturais na marcação de células sanguíneas, reduzindo a captação do Tc-99m nas hemácias, como Thuya occidentalis (Oliveira et al., 1996), Paullinia cupana (Oliveira et al., 2002) e Coffee beans (Oliveira et al., 2003). Sabe-se que a forma das células depende da organização das proteínas presentes na membrana plasmática, portanto quando uma droga sintética ou natural altera a morfologia de uma célula, provavelmente está alterando também as estruturas protéicas, justificando ainda essa diminuição na marcação das hemácias e aumento da expressão do radiofármaco livre pela competição com a proteína ricina.

\section{REFERÊNCIAS}

Agra MF, França PF, Barbosa-Filho JM 2007. Synopsis of the plants known as medicinal and poisonous in Northeast of Brazil. Rev Bras Farmacogn 17: 114-140.

Agra MF, Silva KN, Basílio IJLD, França PF, Barbosa-Filho JM
2008. Survey of medicinal plants used in the region Northeast of Brazil. Rev Bras Farmacogn 18: 472508.

Bernardo-Filho M, Santos-Filho SD, Moura EG, Maiworm $\mathrm{AI}$, Orlando, MMC, Penas ME, Cardoso VN, Bernardo LC, Brito LC 2005. Drug interation with radiopharmaceuticals: a Review. Braz Arch Biol Tech 48: 13-27.

Corrêa MP 1984. Dicionário das Plantas Úteis do Brasil e das Exóticas Cultivadas. Ed. Imprensa Nacional 63.

Hwang JJ, Liao MH, Yen TC, Wey SP, Lin KJ, Pan WHT, Chen JC, Ting G 2002. Biodistribution study of $\left[{ }^{99 \mathrm{~m}} \mathrm{Tc}\right]$ TRODAT-1 alone or combined with other dopaminergic drugs in mice with macroautoradiography. Appl Radiat Isotopes 57: 3542.

Lugnier AAJ, Creppy EE, Dirheimer G 1980. La ricine, protéine toxique du ricin (Ricinus communis L.) - Structure et propriétés. Pathol Biol 28: 127-139.

Oliveira JF, Braga ACS, Ávila AS, Fonseca LMB, Gutfilen B, Bernardo-Filho M 1996. Effect of Thuya occidentalis on the labeling of red blood cells and plasma proteins with Technetium-99m. Yale J Biol Med 69: 489-494.

Oliveira JF, Ávila AA, Braga ACS, Oliveira MBN, Boasquevisque EM, Jales RJ, Cardoso VN, BernardoFilho M 2002. Effect of extract of medicinal plants on the labeling of blood elements with technetium- $99 \mathrm{~m}$ and on the morphology of red blood cells: I- a study with Paullinia cupana. Fitoterapia 73: 305-312.

Oliveira JF, Santos-Filho SD, Catanho MTSA, Srivastava SC, Lima-Filho GL, Bernardo-Filho M 2003. Effect of extract of medicinal plants on the labelling of blood elements with technetium-99m and on the morphology of red blood cells (RBC): toxicological actions of roast Coffee beans (Coffea arabica). Indian J Nuc Med 18: 52-56.

Olsnes S 2004. The history of ricin, abrin and related toxins. Toxicon 44: 361-370.

Paoli S, Dias APM, Capriles PVSZ, Costa TEMM, Fonseca AS, Bernardo-Filho M 2008. Effects of a tomato (Solanum lycopersicum) extract on the labeling of blood constituents with technetium-99m. Rev Bras Farmacogn 18: 190-196.

Souza IA, Santana CF, Martins DG, Santos ER, Lins LJP 1994. Novas observações sobre propriedades antineoplásicas da fracção não-oleosa da semente do Ricinus communis, cultivado no Estado de Pernambuco e sua associação com a radiação ionisante do $\mathrm{Co}^{60}$. Rev Port Farm 44: 139-143. 